\title{
Discrimination of freshwater fish species by Matrix-Assisted Laser Desorption/Ionization-Time Of Flight Mass Spectrometry (MALDI-TOF MS): a pilot study
}

\author{
Pietro VOLTA, ${ }^{*}$ Nicoletta RICCARDI, Rosaria LAUCERI and Mauro TONOLLA ${ }^{1 *}$ \\ CNR Institute of Ecosystem Study, L.go Tonolli 50, 28922 Verbania Pallanza, Italy; ${ }^{1}$ Cantonal Institute of Microbiology, Via Mirasole \\ 22A, 6500 Bellinzona, Switzerland \\ *Corresponding author: p.volta@ise.cnr.it; mauro.tonolla@ti.ch
}

\begin{abstract}
In this study we discriminate three freshwater fish species (the shad Alosa agone Scopoli 1786, the whitefish Coregonus macrophthalmus Nüsslin1882 and the roach Rutilus rutilus Linnaeus 1758) by Matrix-Assisted Laser Desorption/Ionization- Time Of Flight Mass Spectrometry (MALDI-TOF MS) using both muscle and liver tissues. The technology enables to analyze tissues after a simple single-step extraction procedure without any further purification. The molecular profile of muscle tissues showed the most intense peaks at $\mathrm{m} / \mathrm{z}$ range of 11,354.0 ( $\pm 2.0 \mathrm{SD}) \mathrm{Da}, 3508.5$ ( $\pm 1.5 \mathrm{SD}$ ) Da and $8567.2( \pm 1.1 \mathrm{SD})$ Da for the shad, the whitefish and the roach respectively. The molecular profiles of liver tissues exhibit most of the highest peak intensities in the range between 2000 and $6000 \mathrm{~m} / \mathrm{z}$ values. The roach shows the clearest pattern with high intensities detected at mass ranges between 3000 and $3550 \mathrm{Da}$ with maxima at m/z 3035.2 ( \pm 0.2$)$ Da and 3468.7 ( \pm 0.3$)$ Da. The shad shows a shared high peak at $\mathrm{m} / z 3429.0$ ( \pm 0.3$) \mathrm{Da}$. The whitefish shows a group of major peaks in the m/z range of 3000-3700 Da with the highest being at 3635 ( \pm 0.3$)$ Da. The overall signal pattern generated is highly specific for each species and, according to cluster analyses based on the total number of peaks, we could discriminate the three species.
\end{abstract}

Key words: proteomic, biodiversity, Rutilus, Coregonus, fish, food control.

Received: July 2011. Accepted: October 2011

\section{INTRODUCTION}

During the last decades several studies have been carried out focusing on biological diversity from a taxonomic and functional point of view and at different levels of organisms organization, from communities to individuals, and, within the latter, from cells to molecules. One of the most common and meaningful tools adopted to study biological diversity in terrestrial and aquatic ecosystems is the identification of markers enabling the unambiguous detection of species and reconstruction of their evolutive history (e.g., Thum 2008; Zemlak 2009; Radulovici et al. 2010). Fishes, of course, were included in these studies (e.g., Bernatchez et al. 1999; Ali et al. 2004; Ward 2009).

Molecular approaches are particularly useful to distinguish among phylogenetically close species and they can be successfully applied to accurately assess species diversity (e.g., Bucklin et al. 2009; Groeneveld et al. 2009), to reveal cryptic and new species (e.g., Belyaeva, and Taylor 2009) and to highlight systematic relation-ships at species and subspecies level (e.g., Bernatchez, and Dodson 1994; Bernatchez 2001; Brunner et al. 2001). For the rapid identification of individuals, the techniques based on nucleotide sequences (still) have the disadvantage of being time consuming and relatively expensive. Moreover, in order to be useful and appropriate, molecular protocols must be rapid, simple to perform, reliable, and comparatively cheap.

Besides the molecular techniques addressing DNA investigation, great emphasis was recently attributed to proteomics, a relatively new scientific discipline that merges protein biochemistry, genome biology and bioinformatics to determine the spatial and temporal expression of proteins in cells, tissues and whole organisms. Because proteomic analyses provides a direct measure of gene expression, it could be used as an ancilliary tool together with genomic approaches.

Within proteomics techniques, Matrix-Assisted Laser Desorption/Ionization- Time Of Flight Mass Spectrometry (MALDI-TOF MS) is a well-established method for the characterisation of organisms such as bacteria, fungi and even viruses through their own specific protein biomarkers (e.g., Wang et al. 1998; Li et al.2000; Williams et al. 2003; Maier et al. 2005; Pignone et al. 2006; Welker 2011). The results of MALDI-TOF MS analysis provide similar to those obtained by genetic molecular analysis and the outcome of MALDI-TOF MS identification is comparable to and as reliable as that originating from established genetic methods (e.g., Caldwell, and Caprioli 2005). These advantages did stimulate a number of studies addressed to improve the effectiveness of this application 
on whole microorganisms (Claydon et al. 1996; Demirev et al. 2001; Moura et al. 2003; Hettick et al. 2004) and on target organs and tissues of animals in ecotoxicology, neurophysiology and food control (e.g., Neupert, and Predel 2005; Mezhoud et al. 2008; Keyvanshokooh et al. 2009; Lu et al. 2010).

The technology has the advantage that whole cells can be analysed after a simple single-step purification procedure without any further preparation steps. The resulting mass spectra display peak patterns that have been shown to be phylogenetic markers (Wynne et al. 2009). For bacteria - or prokaryotes in general - it has been shown that the peaks recorded in MALDI-TOF mass spectra can be assigned partially to ribosomal proteins (Teramoto 2009; Kallow et al. 2010), thus representing biomarkers that can be exploited for taxonomic studies (Kroppenstedt et al. 2005) and routine identification (Freiwald, and Sauer 2009).

Although MALDI-TOF MS analysis seems to be a promising tool for nematods (Perera et al. 2005a), different insect taxa (Perera et al. 2005b; Feltens et al. 2010; Kaufman et al. 2011), bivalves (Lopez et al. 2005), a literature survey suggests that, to date, only one study has been made to exploit this method for the characterization of fish species (Mazzeo et al. 2008).

In this study we use MALDI-TOF MS on muscle and liver of three commercial freshwater fish species very common in large Italian lakes (the shad Alosa agone (Scopoli 1786) the whitefish Coregonus macrophthalmus (Nusslin 1882) and the roach Rutilus rutilus (Linnaeus 1758 ) in order to detect possible $\mathrm{m} / \mathrm{z}$ markers typical of each species and to enable their unambiguous identification. If the MALDI-TOF MS technique could be proved to work reliably on these organisms, its application could contribute not only to the improvement of the knowledge of freshwater fish, their management and conservation, but also to the anti-fraud control system and, consequently, to the safety and the health of fish consumers also according to the recent regulations of the European Union (Council regulation (EC) No. 104/2000 and 2065/2001 of the European Parliament).

\section{MATERIALS AND METHODS}

Fish sampling and preparation before MALDI-TOF analyses

Three specimens of roach, shad and whitefish were randomly chosen within the commercial catch of Lake Maggiore in March 2008. As soon as they were caught, the fishes were immediately put in the ice and successively stored in a refrigerated room $\left(4^{\circ} \mathrm{C}\right)$. In the lab they were measured (total length Lt, total weight $\mathrm{Wt}$ ), aged and sexed. For each fish, meat flesh was taken from the dorsal region, just in front of the dorsal fin and above the lateral line. Livers were excised. Both tissues were frozen individually at $20{ }^{\circ} \mathrm{C}$ before the analyses. Sample characteristics are described in Tab. 1.

Extraction of muscle tissue proteins

Fish muscle were first cut in small pieces of 0.1-0.2 g aliquots and were extracted during 1 hour at room temperature in $0.2 \mathrm{~mL}$ of $15 \%$ formic acid. The samples were than centrifuged at $10,000 \mathrm{rpm}$ for $5 \mathrm{~min}$ and aliquots of $0.5 \mu \mathrm{L}$ of supernatants were deposited onto a MALDI target plate (Fleximass, Shimadzu) and dried at room temperature $(5 \mathrm{~min})$. Finally $0.5 \mu \mathrm{L}$ of a saturated matrix solution of sinapinic acid (40 mg mL 1) containing 50\% acetonitrile (ACN) in $0.1 \%$ TFA was deposited onto each well and dried under ambient conditions.

\section{MALDI-TOF MS analysis}

Protein mass fingerprints were obtained using a MALDI-TOF Mass Spectrometry AximaTM Confidence machine (Shimadzu-Biotech Corp., Kyoto, Japan), in the linear, positive mode at a laser frequency of $50 \mathrm{~Hz}$ and within a mass range of 2000-20,000 Da. Acceleration voltage was $20 \mathrm{kV}$, and the extraction delay time was 200 ns. A minimum of 20 laser shots per sample was used to generate each ion spectrum. For each sample, a total of 50 protein mass fingerprints were averaged and processed using the Launchpad ${ }^{\mathrm{TM}}$ v. 2.8 software (ShimadzuBiotech Corp.). For peak acquisition the average smoothing method was chosen, with a smoothing filtering width of 50 channels. Peak detection was performed through the threshold-apex peak detection method using the adaptive voltage threshold which roughly follows the signal noise level, and subtraction of the baseline was set with a baseline subtraction filter width of 500 channels. For each sample, a list of the significant spectrum peaks was generated that included the $\mathrm{m} / \mathrm{z}$ values for each peak, mass

Tab. 1. Characteristics of the fish analyzed in this study: the shad (Alosa agone), the whitefish (Coregonus macrophthalmus) and the roach (Rutilus rutilus).

\begin{tabular}{lcccc}
\hline Species & $\begin{array}{c}\text { Total Length } \\
(\mathrm{cm})\end{array}$ & $\begin{array}{c}\text { Total weigth } \\
(\mathrm{g})\end{array}$ & Sex & $\begin{array}{c}\text { Age } \\
(\mathrm{y})\end{array}$ \\
\hline \multirow{3}{*}{ Alosa agone } & & & & \\
& 25.4 & 144.1 & $\mathrm{~F}$ & 2 \\
& 27.8 & 161.9 & $\mathrm{~F}$ & 2 \\
& 27.0 & 169.0 & $\mathrm{~F}$ & 2 \\
Coregonus macrophthalmus & 31.3 & 212.9 & $\mathrm{M}$ & 4 \\
& 28.6 & 180.6 & $\mathrm{M}$ & 4 \\
& 32.3 & 253.5 & $\mathrm{~F}$ & 4 \\
Rutilus rutilus & & & & \\
& 24.1 & 142.2 & $\mathrm{~F}$ & 4 \\
& 24.2 & 148.5 & $\mathrm{~F}$ & 3 \\
& 25.7 & 147.2 & $\mathrm{M}$ & 5 \\
\hline
\end{tabular}



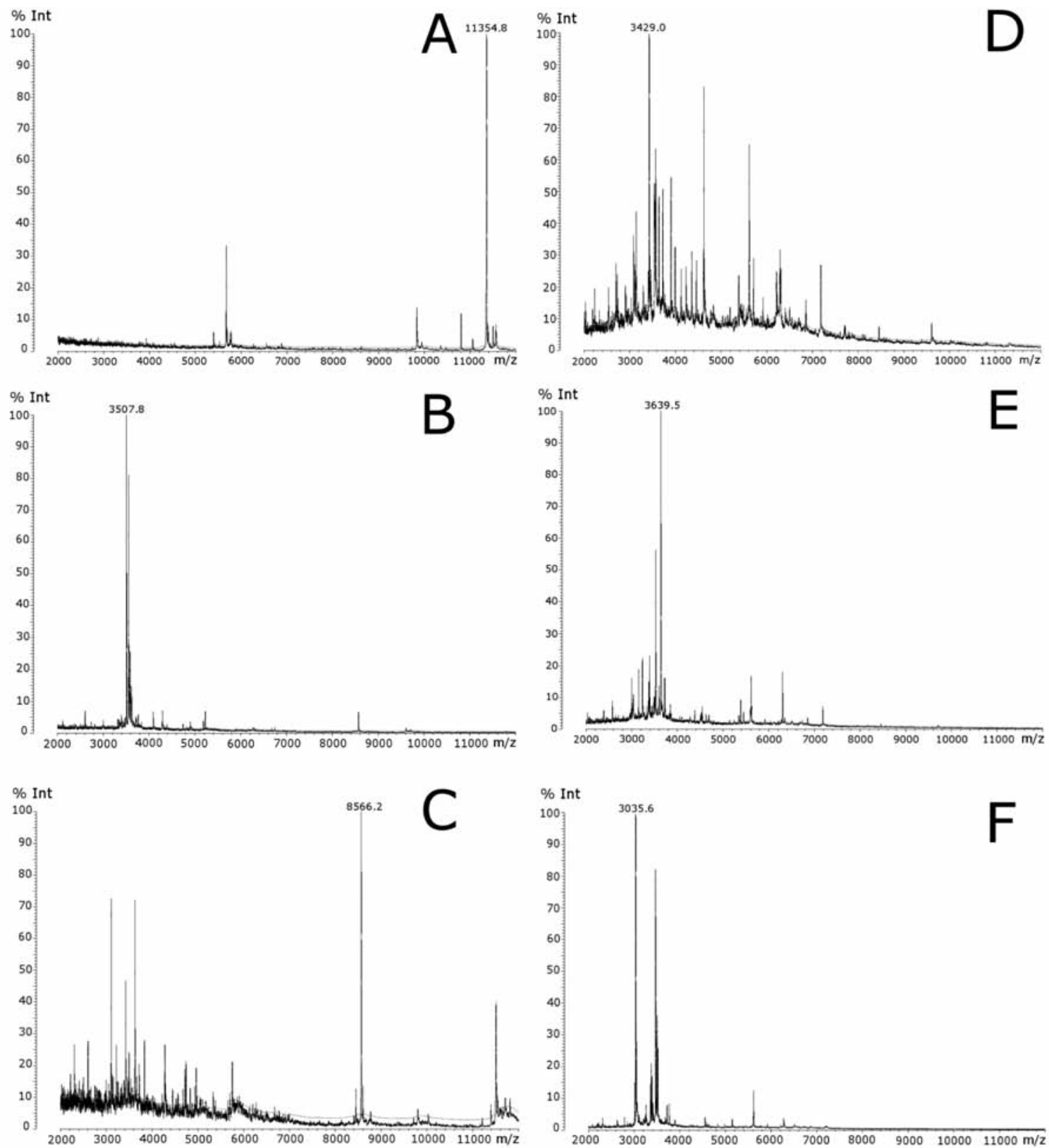

Fig. 1. Example of $\mathrm{m} / \mathrm{z}$ spectra of muscle and liver of Alosa agone (A, D), Coregonus macrophthalmus (B, E) and Rutilus rutilus (C, F). Peak values are expressed in Da.

deviations, and signal intensity. Calibration was conducted for each target plate using spectra of the reference strain Escherichia coli K12 (GM48 genotype). E. coli K12 was deposited on each plate in two fixed positions and the calibration was performed at the beginning of each plate acquisition. At the end a second measurement of K12 as control was performed.

\section{MALDI-TOF MS spectra analysis}

Generated protein mass fingerprints (peak lists) were then imported into the SARAMIS ${ }^{\text {TM }}$ software (Spectral
ARchive And Microbial Identification System, AnagnosTec $\mathrm{GmbH}$ ) and analyzed using the following pre-setting parameters: mass range from 2000 to 20,000 Da, allowed mass deviation of $800 \mathrm{ppm}$. The individual mass spectra were analysed by cluster analysis, applying the single link agglomerative clustering algorithm in SARAMIS ${ }^{\text {TM }}$. For the clustering, peak intensities were not considered.

\section{RESULTS AND DISCUSSION}

Mass spectra acquired in the $\mathrm{m} / \mathrm{z}$ range 2000-20,000 Da revealed strong mass signals between a $\mathrm{m} / \mathrm{z}$ range of 
2000-12,000 Da both for muscle and liver. Examples of molecular profiles obtained from muscle and liver tissues of each species are reported in Fig. 1. The molecular profile of muscle tissues of the shad showed few notable peaks, the highest being at 11,354.0 ( $\pm 2.0 \mathrm{SD}) \mathrm{Da}$ (Fig. 1A). The whitefish muscle generated the highest signals in the $\mathrm{m} / \mathrm{z}$ range between 3500 and 3600 with a prominent one at 3508.5 ( $\pm 1.5 \mathrm{SD}) \mathrm{Da}$ (Fig. 1B). The roach instead showed the highest $\mathrm{m} / \mathrm{z}$ value at $8567.2( \pm 1.1 \mathrm{SD}) \mathrm{Da}$, although most of the peaks were located between 2000 and $6000 \mathrm{Da}$ (Fig. 1C).

Shad liver exhibits most of the highest peak intensities in the $\mathrm{m} / \mathrm{z}$ range between 2000 and $6000 \mathrm{Da}$ values with the most prominent peak at $\mathrm{m} / \mathrm{z} 3429.0( \pm 0.8) \mathrm{Da}$ (Fig. 1D). The whitefish show a group of high peaks in the range $3000-3700 \mathrm{~m} / \mathrm{z}$ with the highest at $\mathrm{m} / \mathrm{z} 3635( \pm 0.3)$ $\mathrm{Da}$ (Fig. 1E). The roach displays the clearest pattern with high intensities detected at mass ranges between 3000 and $3550 \mathrm{Da}$ with a maximum at $3035.2( \pm 0.2) \mathrm{Da}$ (Fig. 1F).

We show that the overall signal pattern generated was highly specific and, according to cluster analyses, we obtained three main groups corresponding to the three different species, both with muscle and liver tissues (Fig. 2).

To the best of our knowledge, only one study have been performed to identify specie-specific molecular profiles and specific $\mathrm{m} / \mathrm{z}$ markers in fish species using MALDI-TOF MS (Mazzeo et al. 2008). In this MALDI TOF MS study they characterized 24 commercial marine fish species such as cod and plaice and only one freshwater fish species (the perch), using muscle samples (fillets). The highest peaks were located in the range between $\mathrm{m} / \mathrm{z}$ 2000 and 16000 Da comparable to our results, and most of the species-specific markers were located within two very narrow $\mathrm{m} / \mathrm{z}$ intervals, the first between 11000 and $12000 \mathrm{Da}$ (mostly around 11400) and the second close to 8400 Da. Mazzeo and coauthors (2008), however, did not evaluate the possibility to discriminate fish species, that was instead the aim of our study.

Our preliminary results suggests that MALDI-TOF MS analysis could provide an alternative or a supplementary method for freshwater fish species identification and discrimination. With respect to methods based on genetics, a proteomic and mass based approach has several advantages. including a reduction of time and costs of analysis. For instance, MALDI-TOF MS application does not require any a priori knowledge of the sample under investigation (e.g. for primer selection) and provides results that are less affected by experimental variables (e.g., DNA extraction, temperature-sensitive restriction).

As clearly stated by Karr (2008), the high potential of MALDI-TOF MS for ecological and evolutionary studies is worthwhile to be explored. Its application to fish biology would be improved by an automation of the analytical procedure which would allow the preparation and analy-

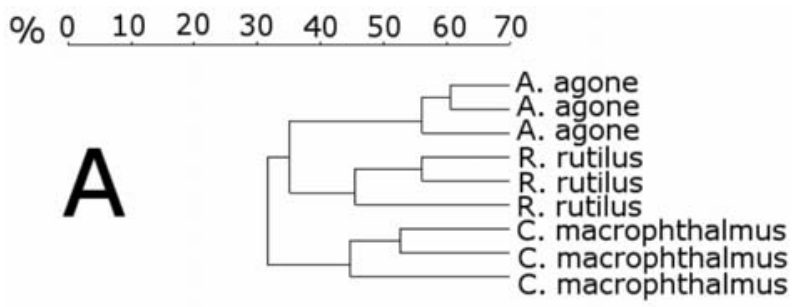

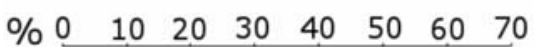

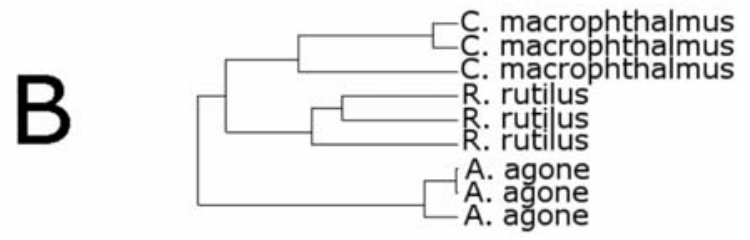

Fig. 2. Cluster analyses of the overall signal pattern generated by the MALDI-TOF MS analyses of Muscle (A) and liver (B) of Alosa agone, Coregonus macrophthalmus and Rutilus rutilus. The individual mass spectra were analysed applying the single link agglomerative clustering algorithm in SARAMIS ${ }^{\mathrm{TM}}$. \% indicates the percentage of similarity.

ses of hundreds of individual samples per day, and the analysis of populations in statistically required numbers. However, a prerequisite is the creation of a taxonomically comprehensive molecular profile data-base for the known fish species, to permit rapid and accurate identification of specimens and provide faster and more detailed characterization of patterns of species distribution and diversity in the light of ecological and evolutionary studies

Moreover, MALDI TOF MS could be used for standard monitoring surveys and analyses of fish products oriented to antifraud controls. In fact, compared to other aquatic organisms, fishes are very important as a human food resource. Recent EU Directives and regulations for quality control have established that the species, the geographical origin and production method must be labelled (Council regulation (EC) No. 104/2000 and 2065/2001 of the European Parliament) in order to guarantee market transparency. Moreover, the European Food Safety Authority has established a comprehensive system of traceability for food (including fishery and aquaculture products) to ensure food safety at all stages (EC Regulation no. 178/2002 of the European Parliament). For these reasons obtaining fast and precise tools to identify each fish species seems a particularly urgent goal in the light of antifraud controls and consumer health protection.

We displayed that it is possible to discriminate different fish species by means of the analyses of both liver and muscle tissues. However the latter are likely more suitable for routine food controls since for several freshwater fish species fillets are more commonly commercialized than the whole fish. 
Finally, it must be emphasised that the results presented here are only a pilot study. Nevertheless, a clear species discrimination was obtained, even though all the settings and statistical algorithms we used were originally designed for the analysis and identification of bacteria and fungi. This suggests that an optimization of both mass spectral analysis and data processing for this particular type of sample is worth performing to exhaustively evaluate the potential of MALDI-TOF MS analysis for studies on freshwater fishes.

\section{ACKNOWLEDGMENTS}

P. Volta was funded by a grant of Fondazione Comunitaria del VCO (Bando Biodiversità 2010), by the WISER FP7 Project (Environment including Climate Change, contract No. 226273), and by CISPP (Commissione Italo-Svizzera per la Pesca). We are grateful to $\mathrm{Mr}$ Igorio Cerutti for the help in laboratory work and to Ms Lindsay Schwarting for the language revision.

\section{REFERENCES}

Ali AA, Huang TA, Qin DN, and Wang XM. 2004. A review of random amplified polymorphic DNA (RAPD) markers in fish research. Rev. Fish Biol. Fish. 14: 443-453.

Belyaeva M, and Taylor DJ. 2009. Cryptic species within the Chydorus sphaericus species complex (Crustacea: Cladocera) revealed by molecular markers and sexual stage morphology. Mol. Phylogenet. Evol. 50: 534-546.

Bernatchez L. 2001. The evolutionary history of brown trout Salmo trutta L. inferred from combined phylogeographic, nested clade and mismatch analyses of mitochondrial DNA variation. Evolution 55: 351-379.

Bernatchez L, and Dodson JJ. 1994. Phylogenetic relationships among Palearctic and Nearctic whitefish (Coregonus sp.) populations as revealed by mitochondrial DNA variation. Can. J. Fish. Aquat. Sci. 51: 240-251.

Bernatchez L, Chouinard A, and Guoqing L. 1999. Integrating molecular genetics and ecology in studies of adaptive radiation: whitefish, Coregonus sp., as a casa study. Biol. J. Linn. Soc. 68: 173-194.

Brunner PC, Douglas MR, Osinov A, Wilson CC, and Bernatchez L. 2001. Holarctic phylogeography of Arctic charr (Salvelinus alpinus) inferred from mitochondrial DNA sequences. Evolution 55: 573-586.

Bucklin A, and Frost BW. 2009.Morphological and molecular phylogenetic analysis of evolutionary lineages within Clausocalanus (Crustacea, Copepoda,Calanoida). J. Crust. Biol. 29: 111-120.

Caldwell RL, and Caprioli RM. 2005.Tissue profiling by mass spectrometry: a review of methodology and applications. Mol. Cell. Proteomics. 4: 394-401.

Claydon MA, Davey SN, Edwards-Jones V, and Gordon DB. 1996. The rapid identification of intact microorganisms using mass spectrometry. Nature Biotechnol. 14: 1584-1586.

Demirev PA, Ramirez J, and Fenselau C. 2001. Tandem mass spectrometry of intact proteins for characterization of biomarkers from Bacillus cereus T spores. Anal. Chem. 73:
5725-5731.

Feltens R, Görner R, Kalkhof S, Gröger-Arndt H, and von Bergen M. 2010. Discrimination of different species from the genus Drosophila by intact protein profiling using matrix-assisted laser desorption ionization mass spectrometry. Bmc Evol. Biol. 10: 95.

Freiwald A, and Sauer S. 2009. Phylogenetic classification and identification of bacteria by mass spectrometry. Nat. Protoc. 4: 732-742.

Groeneveld LF, Lenstra JA, Eding H, Toro MA, Scherf B, Pilling D, Negrini R, Finlay EK, Jianlin H, Groeneveld E, Weigend S, and The GLOBALDIV Consortium. 2010. Genetic diversity in farm animals - a review. Anim. Genet. 41: 6-31.

Hettick JM, Green BJ, Buskirk AD, Kashon ML, Slaven JE, Janotka E, Blachere FM, Schmechel D, and Beezhold DH. 2008. Discrimination of Aspergillus isolates at the species and strain level by matrix-assisted laser desorption/ionization time-of-flight mass spectrometry fingerprinting. Anal. Biochem. 380: 276-281.

Li TY, Liu BH, and Chen C. 2000 Characterization of Aspergillus spores by matrix-assisted laser desorption/ionization time-of-flight mass spectrometry. Rapid Commun. Mass Spectrom. 14: 2393-2400.

López JL, Abalde SL, and Fuentes J. 2005. Proteomic approach to probe for larval proteins of the mussel Mytilus galloprovincialis, Mar. Biotechnol. 7: 396-404.

Lu J, Zheng J, Liu H, Li J, Chen H, and Keping C. 2010. Protein profiling analysis of skeletal muscle of a pufferfish, Takifugu rubripes. Mol. Biol. Rep. 37: 2141-2147.

Kallow W, Erhard M, Shah HN, Raptakis E and Welker M. 2010. MALDI-TOF MS and microbial identification: years of experimental development to an established protocol. In: Shah HN, Gharbia SE, and Encheva V (Eds), Mass spectrometry for microbial proteomics. Wiley, Chichester,UK: $276 \mathrm{pp}$.

Karr TL. 2008. Application of proteomics to ecology and population biology. Heredity 100: 200-206.

Kaufman C, Ziegler D, Schaffner F, Carpenter S, Pflueger V, and Mathis A. 2011. Evaluation of matrix-assisted laser desorption/ionization time of flight mass spectrometry for characterization of Culicoides nubeculosus biting midges. Med. Vet. Entomol. 25: 32-38.

Keyvanshokooh MR, Kalbassi S, Hosseinkhani S, and Vaziri B. 2009. Comparative proteomics analysis of male and female Persian sturgeon (Acipenser persicus) gonads. Anim. Reprod. Sci. 111: 361-368.

Kroppenstedt RM, Mayilraj S, Wink JM, Kallow W, Schumann P, Secondini C, and Stackebrandt E. 2005. Eight new species of the genus Micromonospora, Micromonospora citrea $\mathrm{sp}$. nov., Micromonospora echinaurantiaca sp. nov., Micromonospora echinofusca sp. nov., Micromonospora fulviviridis sp. nov., Micromonospora inyonensis sp. nov., Micromonospora peucetia sp. nov., Micromonospora sagamiensis sp. nov., and Micromonospora viridifasciens sp. nov. Syst. Appl. Microbiol. 28: 328-339.

Mazzeo MF, Giulio BD, Guerriero G, Ciarcia G, Malorni A, Russo GL, and Siciliano RA. 2008. Fish authentication by MALDI-TOF mass spectrometry. J. Agric. Food Chem. 56: 11071-11076. 
Mezhoud K, Praseuth D, Puiseux-Dao S, François J, Bernard C, and Edery M. 2008. Global quantitative analysis of protein expression and phosphorylation status in the liver of the medaka fish (Oryzias latipes) exposed to microcystin-L.R.I. Balneation study. Aquat. Toxicol. 86:166-175.

Moura H, Ospina M, Woolfitt AR, Barr JR, and Visvesvara GS. 2003. Analysis of four human microsporidian isolates by MALDI-TOF mass spectrometry. J. Eukaryot. Microbiol. 50: 156-163.

Neupert S, and Predel R. 2005. Mass spectrometric analysis of single identified neurons of an insect. Biochem. Biophys. Res. Commun. 327: 640-645.

Perera MR, Vanstone VA, and Jones MGK. 2005a. A novel approach to identify plant parasitic nematodes using matrixassisted laser desorption/ionization time-of-flight mass spectrometry. Rapid Comm. Mass Spectrom. 19: 1454-1460.

Perera MR, Vargas RDF, and Jones MGK. 2005b. Identification of aphid species using protein profiling and matrix-assisted laser desorption/ionization time-of-flight mass spectrometry. Entomol. Exp. Appl. 117: 243-247.

Pignone M, Greth KM, Cooper J, Emerson D, Tang J. 2006. Identification of Mycobacteria by Matrix-Assisted Laser Desorption Ionization-Time-of-Flight Mass Spectrometry. J. Clin. Microbiol. 44: 1963-1970.

Radulovici AE, Archambault P, and Dufresne F. 2010. DNA barcodes for marine biodiversity: moving fast forward? Diversity 2: 450-472.

Teramoto K. 2009. Rapid Identification and Classification of
Bacteria Using Ribosomal Protein as Biomarkers by Matrix-Assisted Laser Desorption/Ionization-Mass Spectrometry. Bunseki Kagaku 58: 971-972.

Thum RA. 2004. Using 18S rDNA to resolve diaptomid copepod (Copepoda: Calanoida: Diaptomidae) phylogeny: an example with the North American genera. Hydrobiologia 519: 135-141.

Wang Z, Russon L, Roser DC, and Long SR. 1998. Investigation of spectral reproducibility in direct analysis of bacterial proteins by matrix-assisted laser desorption/ionization time offlight mass spectrometry. Rapid Commun. Mass Spectrom. 12: 456-464.

Ward RD, Hanner R, and Hebert PDN. 2009. The campaign to DNA barcode all fishes, FISH-BOL. J. Fish Biol. 74: 329356.

Welker M. 2011. Proteomics for routine identification of microorganisms. Proteomics 11: 1-11.

Williams TL, Andrzejewski D, Lay JO, and Musser SM. 2003. Experimental factors affecting the quality and reproducibility of MALDI TOF mass spectra obtained from whole bacteria cells, J. Am. Soc. Mass Spectrom. 14: 342-351.

Wynne C, Fenselau C, Demire P, and Edwards N. 2009. Topdown identification of protein biomarkers in bacteria with unsequenced genomes. Anal. Chem. 81: 9633-9642.

Zemlak TS, Ward RD, Connell AD, Holmes BH, and Hebert PDN. 2009. DNA barcoding reveals overlooked marine fishes. Mol. Ecol. Resour. 9: 237-242. 